\title{
Colostrum supplementation with $n-3$ fatty acids alters plasma polyunsaturated fatty acids and inflammatory mediators in newborn calves
}

\author{
Julie Opgenorth, ${ }^{1} \odot$ Lorraine M. Sordillo, ${ }^{2} \odot$ Adam L. Lock, ${ }^{1} \odot$ Jeff C. Gandy, ${ }^{2} \odot$ and Michael J. VandeHaar ${ }^{1 *} \odot$ \\ ${ }^{1}$ Department of Animal Science, Michigan State University, East Lansing 48824 \\ ${ }^{2}$ Department of Large Animal Clinical Sciences, Michigan State University, East Lansing 48824
}

\begin{abstract}
Calves may experience increased oxidative stress at birth through activation of metabolic and respiratory processes. Reducing oxidative stress may enhance calf viability in early life. Our objective was to determine the dose response to fish and flaxseed oil when supplemented in colostrum on concentrations of plasma fatty acid (FA), FA metabolites, and index of oxidative stress during the critical first week of life in calves to understand how supplementing n-3 FA may decrease oxidative stress. We hypothesized that n-3 FA supplemented in colostrum in a linear dose-dependent fashion would associate with increased plasma n-3 FA concentrations and decreased oxidative stress. Twenty-four male and female Holstein calves were randomly assigned to receive $0,30,60$, or $120 \mathrm{~mL}$ of a $1: 1$ fish to flaxseed oil supplement in colostrum. All calves received $2.8 \mathrm{~L}$ of previously frozen colostrum $(\geq 22 \%$ Brix) with their respective treatment within $6 \mathrm{~h}$ after birth. Blood was sampled before first feeding after birth and on d 1, 2, 4, 7 , and $14 \mathrm{~d}$ of age to assess oxidant status and plasma free PUFA, phospholipid FA, and oxylipid concentrations. Health indicators were observed daily. Indicators of general health and growth were unaffected by treatment. Supplemented calves exhibited greater concentrations of n-3 FA in plasma as free and phospholipid FA and some n-3 and n-6 FA-derived oxylipids in the first week of life in a linear fashion with increasing supplemental dose. Fish and flaxseed oil treatments did not alter oxidant status but overall decreased isoprostane concentrations in plasma, indicating oxidative stress was decreased. Together, these responses indicate that the fish and flaxseed oil supplement was antiinflammatory. In conclusion, supplementing colostrum with 30, 60 , and $120 \mathrm{~mL}$ of a 1:1 mixture of fish and flaxseed oil linearly increased plasma concentrations of n-3 FA
\end{abstract}

Received December 11, 2019.

Accepted July 5, 2020.

*Corresponding author: mikevh@msu.edu and metabolites and decreased biomarkers of oxidative stress, but did not alter oxidant status or affect health or growth. Our findings suggest neonatal calves may benefit from n-3 FA supplementation in colostrum to encourage a greater antiinflammatory state.

Key words: oxylipids, polyunsaturated fatty acids, colostrum supplement

\section{INTRODUCTION}

Parturition and the associated physiological changes that accompany it are stressful to the dam and calf (Ling et al., 2018), contributing to an increased risk of immune dysfunction and oxidative stress. Though acute inflammation aids normal parturition (Hansen et al., 2017), unresolved inflammation and oxidative stress can lead to increased disease incidence in the cow (Bradford et al., 2015) and decreased calf vitality (Abuelo et al., 2013).

Oxidative stress occurs in the neonate just after birth as oxygen concentrations entering tissues increase rapidly, resulting in production of reactive oxygen and nitrogen species (RONS; Frank and Sosenko, 1987). The overproduction of RONS and associated free radicals may prove toxic to newborn tissues if antioxidant defense mechanisms are overwhelmed (Buonocore et al., 2001). Additionally, dystocia can decrease neonatal plasma concentrations of vitamins with antioxidant properties such as vitamins $\mathrm{A}$ and $\mathrm{C}$ and $\beta$-carotene, along with a concurrent increase in cortisol (Civelek et al., 2008). These changes further affect the balance between free radical production and the capacity of antioxidants to mitigate them.

Supplementation of calves with fish or flaxseed oils, both of which are enriched for n-3 fatty acids (FA), seems to improve health and growth of milk-fed calves (Ballou and DePeters, 2008; Hill et al., 2011; Karcher et al., 2014). Ballou and DePeters (2008) found that fish oil reduces signs of disease and the acute phase response during an endotoxemic challenge. Karcher et al. (2014) compared fish and flaxseed oils and found both oils decrease inflammatory cytokine gene expression, 
but flaxseed oil enhances feed efficiency in early life and reduces fever after vaccination. Hill et al. (2011) fed a diversified fat supplement containing flaxseed oil to improve feed efficiency and decrease disease incidence. In each of these studies, calves received their n-3 FA supplement as part of their milk replacer feeding program, starting several days after birth. However, the best time to supplement n-3 FA might be at birth when oxidative stress is likely to occur.

Compared with milk at 5 mo after parturition, colostrum collected within the first $24 \mathrm{~h}$ has more fat (5.3 vs. $3.7 \%$ ) with a smaller n-6:n-3 FA ratio (3 vs. 7; Contarini et al., 2014). Provision of n-3 FA to cows before calving does little to increase n-3 FA concentrations in blood of calves (Moallem and Zachut, 2012). Thus, supplementation of n-3 FA in colostrum might be a reasonable approach. We recently found that supplementing calves with a $60 \mathrm{~mL}$ of 1:1 mixture of fish:flaxseed oil along with $200 \mathrm{mg}$ of $\alpha$-tocopherol in colostrum decreased oxidant status index (OSi) during the first week of life (Opgenorth et al., 2020). Oxidant status is the ratio of the concentrations of RONS to antioxidants, so a decreased oxidant status indicates that supplemented calves had less oxidative stress. Our supplement contained n-3 FA and $\alpha$-tocopherol, which both have antioxidant properties, so whether the benefit of our treatment was due to n-3 FA-enriched oils, $\alpha$-tocopherol, or both was not known. Because calves on both treatments received $\alpha$-tocopherol, albeit in different dosages, we postulated that the major benefit was from the fish and flax oils. In the current study, we supplemented calves with n-3 FA without additional $\alpha$-tocopherol. In addition, to examine possible mechanisms, we measured blood concentrations of inflammatory markers and oxylipids. Oxylipids, which are produced from enzymatic oxidation of n-3 FA, promote resolution of inflammation and repair of oxidative tissue damage (Raphael and Sordillo, 2013).

Therefore, the objective of our current study was to determine effects of 3 doses of a 1:1 blend of fish and flaxseed oils (without extra $\alpha$-tocopherol) on plasma FA composition and OSi, on the concentration of several oxylipids and inflammatory markers in blood, and on health and growth. We hypothesized that an n-3 FA supplement would increase plasma n-3 FA concentrations in a linear, dose-dependent manner, leading to an increase in the biosynthesis of antiinflammatory n-3 FA-derived oxylipids and decreased oxidative stress.

\section{MATERIALS AND METHODS}

The study was conducted from June to July of 2018 at the Michigan State University (MSU) Dairy Teaching and Research Center (East Lansing) and was ap- proved by the MSU Animal Care and Use Committee (approval no. 03/18-035-00). Calves were born between June 3 and July 17 and housed in outdoor hutches under shade. Throughout the course of the study, outside temperature averaged $21^{\circ} \mathrm{C}$ and the minimum and maximum temperatures were $6^{\circ} \mathrm{C}$ and $34^{\circ} \mathrm{C}$, respectively.

\section{Experimental Design}

Twenty-four Holstein (12 male, 12 female) calves were assigned to 1 of 4 treatment groups in a randomized block design by sex. Treatments followed a pattern of varying amounts of a 1:1 mixture of fish:flaxseed oil, which also included polysorbate- 80 at $0.2 \mathrm{~mL} / \mathrm{mL}$ of oils to emulsify the oils and enhance absorption. Treatments were assigned as follows: (1) control: no supplement in colostrum (CON), (2) $30 \mathrm{~mL}$ of 1:1 fish: flaxseed oil blend in colostrum (FF30), (3) $60 \mathrm{~mL}$ of 1:1 fish:flaxseed oil blend in colostrum (FF60), and (4) $120 \mathrm{~mL}$ of 1:1 fish:flaxseed oil blend in colostrum (FF120).

Colostrum from cows in the MSU herd was frozen in pouches of $2.8 \mathrm{~L}$ for later use if it scored $\geq 22 \%$ on the Brix scale (indicating $\geq 50 \mathrm{~g} / \mathrm{L}$ immunoglobulins: Bielmann et al., 2010). Each calf received a randomly assigned pouch. The pouches were thawed and sampled for immunoglobulin concentration. The supplement for treatment calves was then added to $2.8 \mathrm{~L}$ of colostrum, but control calves did not receive any supplement. Calves were fed colostrum within $6 \mathrm{~h}$ after birth (average was $3.6 \mathrm{~h}$ ); if a calf did not consume by suckling, the colostrum was delivered by intragastric tube. After birth, all calves were removed from the dam immediately and received a bovine rotavirus and coronavirus vaccine and intramuscular supplements of $1 \mathrm{~mL}$ of Vitamin $\mathrm{A}$ and D VetOne, equivalent to $500 \mathrm{kIU}$ of vitamin A and $75 \mathrm{kIU}$ of vitamin $\mathrm{D}_{3}$ (MWI Animal Health, Boise, ID) and $2 \mathrm{~mL}$ BO-SE (Merck Animal Health, Madison, NJ), which contains $50 \mathrm{mg}$ of $\alpha$-tocopherol and $1 \mathrm{mg}$ of selenium per $\mathrm{mL}$. A second colostrum feeding of $1.9 \mathrm{~L}$ was given 12 to $18 \mathrm{~h}$ after birth, but no supplement was added to the second feeding for any calves.

Calves were housed outside after their first day of life in individual calf hutches bedded with sand and were isolated to prevent physical contact with other calves. They were provided with ad libitum access to water and calf starter grain (Ampli-Calf as starter 20P R50, $20 \%$ protein; Land O'Lakes, Arden Hills, MN) and fed daily with milk replacer (Cow's Match WarmFront Milk Replacer, $27 \%$ protein and 10\% fat; Land O'Lakes) at approximately 0900, 1600, and $2100 \mathrm{~h}$. Each liter of milk replacer contained $13 \%$ solids. Milk replacer was given 3 times per day at 0900, 1600, and $2100 \mathrm{~h}$. Age 0 to 1 wk calves received $2.4 \mathrm{~L}$ at the morning and 
afternoon feeding and $2.8 \mathrm{~L}$ in the evening. Calves 1 to 6 wk of age received $2.8 \mathrm{~L}$ at the morning and afternoon feeding and $3.8 \mathrm{~L}$ in the evening. At 6 to $8 \mathrm{wk}$, calves received $3.8 \mathrm{~L}$ in the morning only. Health was scored for 2 wk after birth. Medication, milk replacer refusal feedings, and disease incidence were recorded throughout the preweaning period. We measured BW with a calibrated calf cart scale (Digi-star, Fort Atkinson, WI) and wither height and heart girth at birth, 2 wk of age, and weaning.

Health was assessed daily for 2 wk after birth by trained researchers blind to treatment before the AM milk feeding. Health scores for feces, eyes, nose, and ears were based on methods by McGuirk, University of Wisconsin, on a 0 to 3 scale where scoring was described as fecal: $0=$ normal to $3=$ watery, discolored, or bloody; eyes: $0=$ no discharge to $3=$ excessive discharge; nose: $0=$ normal discharge to $3=$ excessive discharge; ear: 0 $=$ normal ear alertness to $3=$ tilted head or blatant ear droop (University of Wisconsin Madison, 2020).

\section{Analysis of n-6 to n-3 FA Ratio in Colostrum}

Twenty microliters of an antioxidant-reducing agent of $50 \%$ methanol, $25 \%$ ethanol, and $25 \%$ water with $0.9 \mathrm{~m} M$ of butylated hydroxytoluene, $0.54 \mathrm{~m} M$ EDTA, $3.2 \mathrm{~m} M$ triphenylphosphine, and $5.6 \mathrm{mM}$ indomethacin, as described in Kuhn et al. (2018), was added to $125 \mu \mathrm{L}$ of thawed colostrum. Samples underwent lipid hydrolysis via the addition of $178 \mu \mathrm{L}$ of $\mathrm{KOH}$ and incubating for $45 \mathrm{~min}$ at $45^{\circ} \mathrm{C}$. Once samples cooled to room temperature, they were centrifuged at 4,800 $\times g$ for $10 \mathrm{~min}$ at $4^{\circ} \mathrm{C}$. The $\mathrm{HCl}$ at $6 \mathrm{M}$ was added to the removed supernatant in increments of $10 \mu \mathrm{L}$ until the supernatant $\mathrm{pH}$ was decreased to 4 or less. A mixture of internal standards of $15 \mu \mathrm{L}$ was added to each sample mixture as well, consisting of $0.25 \mu M$ $15(\mathrm{~S})$-hydroxyeicosatetraenoic- $d_{8}, 0.5 \mu M$ 8(9)-epoxyeicosatrienoic acid- $d_{11}, 0.5 \mu M$ prostaglandin $\mathrm{E}_{2}-d_{9}$, and $0.25 \mu M$ 8,9-dihydroxyeicosatrienoic acid- $d_{11}$. Samples underwent solid-phase extraction with Oasis HLB 12 cc LP extraction columns (Waters, Milford, MA) via a Biotage ExtraHera (Biotage, Charlotte, NC), further described in Putman et al. (2019). Samples were then dried in a Savant SpeedVac (Thermo Fisher Scientific, Waltham, MA) and reconstituted in 1.5:1 methanol: HPLC water. After filtration, samples were placed in glass vials with inserts and stored at $-20^{\circ} \mathrm{C}$ until liquid chromatography/MS analysis.

\section{Blood Collection and Analysis}

Blood was collected from the jugular vein of calves on d 0 (before first colostrum feeding), 1 (24 $\pm 4 \mathrm{~h}$ ),
$2(48 \pm 4 \mathrm{~h}), 4( \pm 1 \mathrm{~d}), 7( \pm 1 \mathrm{~d})$, and $14( \pm 2 \mathrm{~d})$ after birth. Analysis of $0 \mathrm{~d}$ samples were used as a covariate in the statistical model, but if not significant, were not included in results. Serum was harvested to determine serum total protein using a digital Brix refractometer and was sent to Saskatoon Colostrum Company for analysis of immunoglobulins (Saskatoon, SK, Canada). Serum was harvested and immediately flash frozen in liquid nitrogen and placed in dry ice during transit to a $-80^{\circ} \mathrm{C}$ freezer for later analysis of OSi. Plasma was harvested immediately and stored at $-20^{\circ} \mathrm{C}$ until analysis of FA phospholipid profiles. Another aliquot of plasma was immediately flash frozen with liquid nitrogen and stored at $-80^{\circ} \mathrm{C}$ for future analysis of oxylipid and free PUFA concentrations.

\section{Oxidant Status Index}

The concentrations of RONS and of antioxidants in serum were measured in the same sample concurrently to calculate OSi. The RONS were measured using the Cell Biolabs Inc. Oxiselect in vitro ROS/RNS assay kit (Cell Biolabs Inc., San Diego, CA). Free radicals in samples convert a dichlorodihydrofluorescein fluorogenic probe to 2',7'-dichlorodihydrofluorescein to detect fluorescence intensity to quantify total free radical concentration as described previously (Putman et al., 2018).

Antioxidant potential (AOP) of the same samples was quantified through the units of Trolox equivalence, a synthetic analog of $\alpha$-tocopherol, where values of AOP were compared with a photometric plate reader. 2,2'-Azino-bis-3-ethylbenzothiazoline-6-sulfonic acid was used as a radical cation to be reduced by antioxidants as described previously (Putman et al., 2018). The reduction potential of each sample, compared as Trolox equivalence, was compared by a photometric plate reader. This decolorization assay is further described in Re et al. (1999).

\section{Plasma Free PUFA, Oxylipids, and Isoprostanes}

Sample Preparation. Extraction and analysis of plasma for analysis of free PUFA, oxylipid, and isoprostane concentrations followed methods modified from Mavangira et al. (2015). In brief, $1 \mathrm{~mL}$ of plasma was thawed on ice and $1 \mathrm{~mL} 4 \%$ formic acid and $4 \mu \mathrm{L} /$ $\mathrm{mL}$ of an antioxidant-reducing agent to protect samples from lipid peroxidation during processing (O'Donnell et al., 2009) was added to plasma. The antioxidantreducing agent was 50\% methanol, $25 \%$ ethanol, and $25 \%$ water with $0.9 \mathrm{mM}$ butylated hydroxytoluene, $0.54 \mathrm{~m} M$ EDTA, $3.2 \mathrm{~m} M$ triphenylphosphine, and 5.6 $\mathrm{m} M$ indomethacin, as described in Kuhn et al. (2018). 
A mixture of internal standards of $15 \mu \mathrm{L}$ was added to each sample mixture as well, consisting of $0.25 \mu \mathrm{M}$ 5 (S)-hydroxyeicosatetraenoic acid- $d_{8}, 0.25 \mu M 15(\mathrm{~S})$-hydroxyeicosatetraenoic acid- $d_{8}, 0.5 \mu M 8(9)$-epoxyeicosatrienoic acid- $d_{11}, 0.5 \mu M$ prostaglandin $\mathrm{E}_{2}-d_{9}$, and 0.25 $\mu M$ 8,9-dihydroxyeicosatrienoic acid- $d_{11}$. Waters Oasis Prime HLB 3cc solid-phase extraction columns were used for solid phase extraction performed by Biotage ExtraHera (Biotage). After samples were loaded onto columns and excess infranatant was discarded with nitrogen, columns were washed with $3 \mathrm{~mL}$ of $5 \%$ methanol and then $2.5 \mathrm{~mL}$ of 90:10 acetonitrile:methanol eluted samples. Leftover solvents were evaporated with a Savant SpeedVac. A mixture of 1.5:1 methanol:HPLC water brought the FA back into solution before filtering and dispensing into glass chromatography vials with inserts.

Quantification of Oxylipids. In short, the quantification of metabolites was accomplished on a Waters Xevo-TQ-S tandem quadrupole mass spectrometer using multiple reaction monitoring. Chromatography separation was performed with an Ascentis Express C18 HPLC column (Sigma-Aldrich, St. Louis, MO), held at $50^{\circ} \mathrm{C}$ and autosampler held at $10^{\circ} \mathrm{C}$. Mobile phase bottle $\mathrm{A}$ was water containing $0.1 \%$ formic acid and mobile phase bottle $\mathrm{B}$ was acetonitrile; the flow rate was $0.3 \mathrm{~mL} / \mathrm{min}$. Liquid chromatography separation took 15 min per sample with linear gradient steps programmed as follows (A:3B ratio): time 0 to $0.5 \mathrm{~min}$ $(99: 1)$, to $(60: 40)$ at $2.0 \mathrm{~min}$; to $(20: 80)$ at $8.0 \mathrm{~min}$; to (1:99) at $9.0 \mathrm{~min} ; 0.5$ min held at (1:99) until min 13.0; then return to $(99: 1)$ at $13.01 \mathrm{~min}$, and held at this condition until $15.0 \mathrm{~min}$. All oxylipids were detected using electrospray ionization in negative-ion mode. Cone voltages and collision voltages were optimized for each analyte using Waters QuanOptimize software and data analysis was carried out with Waters MassLynx software.

Quantification of Isoprostanes. Quantification of isoprostanes was accomplished with a Waters Xevo TQ-S tandem quadrupole mass spectrometer using multiple reaction monitoring. Chromatography separation was performed with a Waters Acquity UPLC utilizing a BEH C18 $1.7 \mu M(2.1 \times 150 \mathrm{~mm})$ column, held at $50^{\circ} \mathrm{C}$, and autosampler held at $10^{\circ} \mathrm{C}$. Mobile phase bottle $\mathrm{A}$ was $0.1 \%$ acetic acid and mobile phase bottle $\mathrm{B}$ was acetonitrile, mobile phase bottle $\mathrm{C}$ was methanol, and the flow rate was $0.3 \mathrm{~mL} / \mathrm{min}$. The gradient initial phase A:B, 80:20 to 1 min changing to A:B:C, $50: 30: 20$, to 7 min changing to A:B:C, 1:80:19, to 7.01 changing back to initial phase and holding until $10 \mathrm{~min}$. All oxylipids were detected using electrospray ionization in negative-ion mode. Cone voltages and collision voltages were optimized for each analyte using Waters QuanOptimize software and data analysis was carried out with Waters MassLynx software.

Quantification of Free Polyunsaturated Fatty Acids. Briefly, reverse-phase liquid chromatography/ MS on a Waters Acquity UPLC employing a BEH C18 $1.7 \mu M(2.1 \times 100 \mathrm{~mm})$ column with a flow rate of 0.6 $\mathrm{mL} / \mathrm{min}$ at $50^{\circ} \mathrm{C}$ was utilized. The quadrupole MS was in electrospray negative ionization mode and voltage was $-3 \mathrm{kV}$ with the turbo ion spray source temperature at $450^{\circ} \mathrm{C}$. The gradient mobile phase was programmed in the following manner $(\mathrm{A} / \mathrm{B} / \mathrm{D}$ ratio): time 0 to 0.5 $\min (30 / 5 / 65)$, to $(65 / 5 / 30)$ at $1.0 \mathrm{~min}$, to $(85 / 10 / 5)$ at $5.50 \mathrm{~min}$, to $(89 / 10 / 1)$ at $7.0 \mathrm{~min}$, and held until 11.5 min, then return to $(30 / 5 / 65)$ at $11.01 \mathrm{~min}$, and held at this condition until $15.0 \mathrm{~min}$. In this gradient mobile phase $\mathrm{A}=$ acetonitrile, $\mathrm{B}=$ methanol, and $\mathrm{D}=0.1 \%$ formic acid. Fatty acids were quantified by matching mass- 1 and retention time with corresponding deuterated internal standard abundance and calibrated to a linear 7-point standard curve $\left(\mathrm{R}^{2}>0.99\right)$ using Waters Empower 3 software.

\section{Plasma Phospholipid Fatty Acid Analysis}

Phospholipids were analyzed using methods adapted from Folch et al. (1957) and Kramer et al. (1997). In brief, total lipids were extracted from an aliquot of 5 $\mathrm{mL}$ of plasma by shaking samples in $6 \mathrm{~mL}$ of methanol and $12 \mathrm{~mL}$ of chloroform. A solution of $2 \%$ sodium chloride in water was then added. The chloroform layer with lipids was filtered out, dried, and weighed for total lipid content. Next, the phospholipid fractions were isolated using solid phase extraction. Columns were initially washed with $1.2 \mathrm{~mL}$ of $7: 1$ acetone:water and eluted with $4 \mathrm{~mL}$ of hexane before loading lipid samples dissolved in $0.8 \mathrm{~mL}$ of hexane:methyl tertbutyl ether:acetic acid (100:3:0.3). Cholesterol esters were first eluted with $14 \mathrm{~mL}$ of hexane, and free FA eluted with $8 \mathrm{~mL}$ of hexane:chloroform:ethyl acetate (100:5:5). Columns were washed with $6 \mathrm{~mL}$ of $2: 1$ chloroform:isopropanol. Next, the triglyceride fraction was collected via $8 \mathrm{~mL}$ of chloroform:methanol:acetic acid (100:2:2), and phospholipids eluted via $10 \mathrm{~mL}$ of methanol:chloroform:water (10:5:4). The phospholipid fraction was then washed with $3 \mathrm{~mL}$ of $5 \%$ sodium chloride in water and phospholipids in the chloroform layer were collected. Only the phospholipid fraction was analyzed in the interest of relevance to experiment objectives.

After phospholipid content was calculated, $0.5 \mathrm{~mL}$ of the internal standard, C17:1 10-heptadecenoic acid in toluene, was added. Phospholipids were then 
methylated into FAME as previously described (Lock et al., 2013). Hexane reconstituted FAME in solvent to produce a $1 \%$ solution for GLC analysis with a GC-2010 Plus gas chromatograph (Shimadzu, Kyoto, Japan). Conditions for GLC analysis are further described in Lock et al., (2013). Plasma phospholipid FA concentrations were calculated as a percentage of total phospholipids recovered from plasma in g/100 g. All values were calculated with average response factor of 130 from external standards. Due to sample number constraints per analysis, samples collected d $0,2,4$, and 7 were analyzed separately from d 1 and 14 and were run consistently with randomized blocks.

\section{Statistical Analysis}

Data were analyzed using SAS version 9.4 (SAS Institute Inc., Cary, NC) with a mixed procedure. Fixed effects were sex, treatment, and day. Random effects were block within sex and calf within block, sex, and treatment. Contrast coefficients were assigned for each treatment to test linear, quadratic, and cubic effects as follows: linear $-7,-3,1$, and 9 ; quadratic $7,-4,-8$, and 5; cubic $-3,8,-6$, and 1 for CON, FF30, FF60, and FF120, respectively. When analyzing statistics for BW and ADG up to weaning, the variable week replaced day. Average daily gain for the first 2 wk of life, health scores, and d 1, 2, 4, and 7 of blood variables were analyzed with the mixed model. Blood variables from d 14 were included in figures but not in statistical analysis, as we expected most variables to return to baseline by d 14. All $P$-values or data expressed in tables are results from analyzing $\mathrm{d} 1,2,4$, and 7 after birth only. After birth and before the first colostrum feeding, blood was sampled and analyzed to use as a potential covariate in the model. If the covariate was not significant and did not correlate with day, it was not included in the model.

Assays were conducted by block. The order on the well plate of the RONS concentration assay significantly affected resulting values, and therefore, was included in the model for OSi analysis as order within block. Effect of block was confounded with order. Treatment was not confounded with order, as treatments were random with respect to order of wells. Preweaning ADG, general health observations, colostrum immunoglobulin count, and Brix measures were analyzed with the general linear model ANOVA procedure.

Normality was assumed if a variable's general linear model procedure's Bartlett homogeneity of variance test indicated $P>0.05$. Data were log-transformed if $P$ $\leq 0.05$ and transformed least squares means were backtransformed from the model for interpretation in tables and figures. Differences were considered significant if $P$ $\leq 0.05$ and a tendency if $0.05<P \leq 0.10$. Differences were considered significant if interaction $P \leq 0.10$ and a tendency if $0.10<P \leq 0.15$.

\section{RESULTS}

\section{Health and Growth}

During the first 2 wk of life, 14 calves were treated for diarrhea. Calves typically showed initial symptoms of diarrhea 10 to $12 \mathrm{~d}$ after birth. Across treatment groups, the average number of medication doses for diarrhea per calf was 1.4 during the first 2 wk of life, and differences between treatments were not significant $(P=0.71)$. If a calf did not complete a meal of milk replacer, it was recorded as one refusal. The average number of refusals per calf was 0.5 during the first 2 wk and was similar across treatment groups $(P=0.64)$. One calf died at $25 \mathrm{~d}$ of age, presumably from heat stress; all available data for this calf were included in the data set. Average health scores over the first $3 \mathrm{wk}$ of life were $1.18,0.17,0.09$, and 0.02 for fecal, eye, nasal, and ear scores, respectively, and were not altered by treatments $(P>0.20)$.

Despite the fact that calves were given treatments by farm staff blinded to treatment, the time of feeding first colostrum was $3.3,2.1,3.8$, and $5.2 \mathrm{~h}$ for the CON, FF30, FF60, and FF120 groups, respectively, and the overall treatment effect was significant $(P=0.02)$. However, the concentrations of immunoglobulins and total protein in serum in calves in the first week were not altered by treatment and were $>10$ and $\geq 52 \mathrm{~g} / \mathrm{L}$, respectively, indicating all calves received colostrum of acceptable quality in a timely fashion for antibody absorption in the bloodstream (Calloway et al., 2002; Godden, 2008). Treatment did not alter serum total protein (mean of $63 \mathrm{~g} / \mathrm{L}$ ) or immunoglobulin concentration (mean of $32 \mathrm{~g} / \mathrm{L})$ during the first week of life $(P$ $>0.9$ for overall treatment effect for both variables). Mean colostrum n-6:n-3 FA ratios before addition of supplements for CON, FF30, FF60, and FF120 were $2.5,3.0,2.7$, and 2.6 , respectively, and did not differ across treatment groups.

Treatment did not alter growth rates in the first 2 wk of life or during the preweaning period $(P>0.20)$. Average wither height, heart girth, and BW gain during the first $2 \mathrm{wk}$ were $0.87 \mathrm{~cm} / \mathrm{d}, 0.72 \mathrm{~cm} / \mathrm{d}$, and 0.60 $\mathrm{kg} / \mathrm{d}$ and were not altered by treatment $(P>0.20)$. Treatment also did not alter BW gain through the entire preweaning period $(0.51,0.64,0.78$, and $0.60 \mathrm{~kg} / \mathrm{d}$ for CON, FF30, FF60, and FF120, respectively; $P=$ $0.31)$. 


\section{Plasma Free PUFA}

Fish and flaxseed oil $(\mathbf{F F})$ treatments increased free concentrations of the n-3 FA $\alpha$-linolenic acid (ALA), eicosapentaenoic acid (EPA), docosahexaenoic acid (DHA), and docosapentaenoic acid in plasma on d 1, 2, 4, and 7 after birth in a linear fashion (Table $1, P$ $<0.001)$. This corresponded well with the FA found in fish and flaxseed oil. DHA was significantly increased in plasma free PUFA concentrations with $\mathrm{FF}$ treatments where CON, FF30, FF60, and FF120 averaged 8, 10, 14 , and $29 \mathrm{n} M$ DHA $(P<0.001)$ during the first week after supplementation. Likewise, EPA also increased with increasing FF supplement volume (0.6, 0.8, 2.7, and $6.0 \mathrm{n} M$, respectively; $P<0.001$ ). The ALA significantly differed in concentration among $\mathrm{CON}$ and $\mathrm{FF}$ treatment calves during the first week of life $(24,46$, 73 , and $140 \mathrm{n} M$, respectively; $P<0.001$ ) as well. All 3 primary n-3 FA concentrations were linearly increased by $\mathrm{FF}$ treatments $(P \leq 0.01)$ on $\mathrm{d} 1,2$, and 4 after birth. By d 7 after birth, concentrations either returned to normal or tended to be elevated $(P \geq 0.09)$ with $\mathrm{FF}$, and by d 14, n-3 FA concentrations all returned to baseline (Figure 1).

Linoleic acid constitutes $15 \%$ of flaxseed oil and is a precursor to arachidonic acid (ARA). Plasma concentrations of free linoleic acid averaged $\sim 2,900 \mathrm{n} M$ in calves given FF treatments, compared with 2,000 nM for CON, but these were not different. Additionally, treatments did not alter concentrations of free ARA in plasma (mean $17 \mathrm{n} M, P=0.75$ for treatments). The concentration of n- 6 FA remained constant for all calves, whereas primary n-3 FA linearly increased in FF treatments. Thus, during the first week of life, the ratio of free n-6:n-3 FA in plasma was decreased with $\mathrm{FF}$ in a linear fashion $(P=0.01 ; 28,16,13$, and 8 for $\mathrm{CON}$, FF30, FF60, and FF120, respectively).

\section{Plasma Phospholipid FA}

The linear trend of increased free n-3 FA and decreased free n-6:n-3 FA ratio was also associated with similar changes in the plasma phospholipid FA fraction (Supplemental Table S1, https://doi.org/10.3168/jds .2019-18045). As expected, supplementing FF increased $(P<0.001)$ the concentrations of ALA, EPA, and DHA in the first week of life (Figure 1; Table 2). The DHA increased linearly $(P<0.001)$ with increasing FF dose, whereas ALA and EPA increased quadratically $(P<$ 0.001 and $P=0.02$, respectively). Treatment did not alter the content of linoleic acid and ARA in phospholipids (both $P>0.11$ ), but linoleic acid had a quadratic effect $(P=0.04)$. The content of total n-3 FA and total PUFA in phospholipids increased with FF supplementation in linear and quadratic fashions $(P=0.02)$. However, the concentration of total n- 6 FA did not change with treatments, although a quadratic upward trend was observed $(P=0.06)$. The ratio of $n-6$ to $n-3$ FA in plasma phospholipid decreased as calves were fed more FF $(7.0,5.5,4.7$, and 3.4) in a linear fashion $(P$ $<0.001)$. The FF treatments linearly decreased monounsaturated plasma phospholipid FA and quadratically altered SFA $(P=0.01, P=0.03$, respectively). For all phospholipid PUFA that were altered by treatment, the concentration in phospholipids decreased over time in calves fed FF treatments $(P \leq 0.02$ for day; Figure 1$)$.

Table 1. Least squares means of plasma free PUFA concentrations on average d 1, 2, 4, and 7

\begin{tabular}{|c|c|c|c|c|c|c|c|c|}
\hline Plasma PUFA ${ }^{1}(\mathrm{n} M)$ & \multicolumn{4}{|c|}{ Treatment $^{2}$} & $\mathrm{~L}^{3}$ & $\mathrm{Q}^{4}$ & $\mathrm{C}^{5}$ & $\begin{array}{c}\text { Overall } \\
P \text {-value }\end{array}$ \\
\hline $\mathrm{C} 18: 2(\mathrm{n}-6 ; \mathrm{LA})$ & 925 & 907 & 1,120 & 1,300 & 0.20 & 0.93 & 0.64 & 0.58 \\
\hline $\mathrm{C} 20: 3(\mathrm{n}-6)$ & 1.11 & 1.88 & 1.48 & 1.75 & 0.07 & 0.74 & 0.53 & 0.26 \\
\hline C20:4 (n-6; ARA) & 16.9 & 14.2 & 16.4 & 22.2 & 0.56 & 0.65 & 0.80 & 0.89 \\
\hline C20:5 (n-3; EPA) & 0.64 & 0.83 & 2.69 & 6.01 & $<0.001$ & 0.69 & 0.14 & $<0.001$ \\
\hline
\end{tabular}

${ }^{1}$ Plasma PUFA: linoleic acid (LA), $\alpha$-linolenic acid (ALA), arachidonic acid (ARA), eicosapentaenoic acid (EPA), and docosahexaenoic acid (DHA). FA = fatty acids.

${ }^{2}$ Treatments $(\mathrm{n}=6): \mathrm{CON}=$ control, no supplement added to colostrum; FF30 $=30 \mathrm{~mL}$ of a 1:1 ratio fish and flaxseed oil blend added to colostrum; FF60 = $60 \mathrm{~mL}$ of a 1:1 ratio fish and flaxseed oil blend added to colostrum; FF120 = 120 mL of a 1:1 ratio fish and flaxseed oil blend added to colostrum.

${ }^{3} \mathrm{~L}=$ linear polynomial contrast.

${ }^{4} \mathrm{Q}=$ quadratic polynomial contrast.

${ }^{5} \mathrm{C}=$ cubic polynomial contrast.

${ }^{6}$ Overall $P$-value $=$ treatment effect $P$-value. 


\section{Oxidant Status Index, Oxylipids, and Isoprostanes}

Average concentrations of oxylipids and isoprostanes for each treatment during wk 1 are reported in Supplemental Tables S2 and S3, respectively (https:/ /doi.org/10.3168/jds.2019-18045). Concentrations of 5 oxylipids and 1 isoprostane in plasma were altered by FF treatments (Figure 2). Calves given FF treatments had linearly increased $(P<0.001)$ EPA-derived 5,6-dihydroxy-eicosatetraenoic acid (5,6-DiHETE) and quadratically increased 14,15 -DiHETE $(P=0.003)$ and 17,18-DiHETE $(P=0.02)$ with supplement dose. The FF treatments increased DHA-derived 19,20-dihydroxy-docosapentaenoic acid (19,20-DiHDPA) by 57,53 , and $55 \%$ of $\mathrm{CON}$, respectively $(P=0.02$ in quadratic fashion). The $\mathrm{n}$-6-derived leukotriene $\mathrm{B}_{4}$ $\left(\mathbf{L T B}_{4}\right)$ increased with FF treatments 100, 166, and $128 \%$ of $\mathrm{CON}(P=0.03$ in quadratic fashion), and 8-iso-prostaglandin- $\mathrm{A}_{2}$ decreased by 59,32 , and $33 \%$ of $\operatorname{CON}(P=0.01$ overall and $P=0.008$ cubic $)$. The
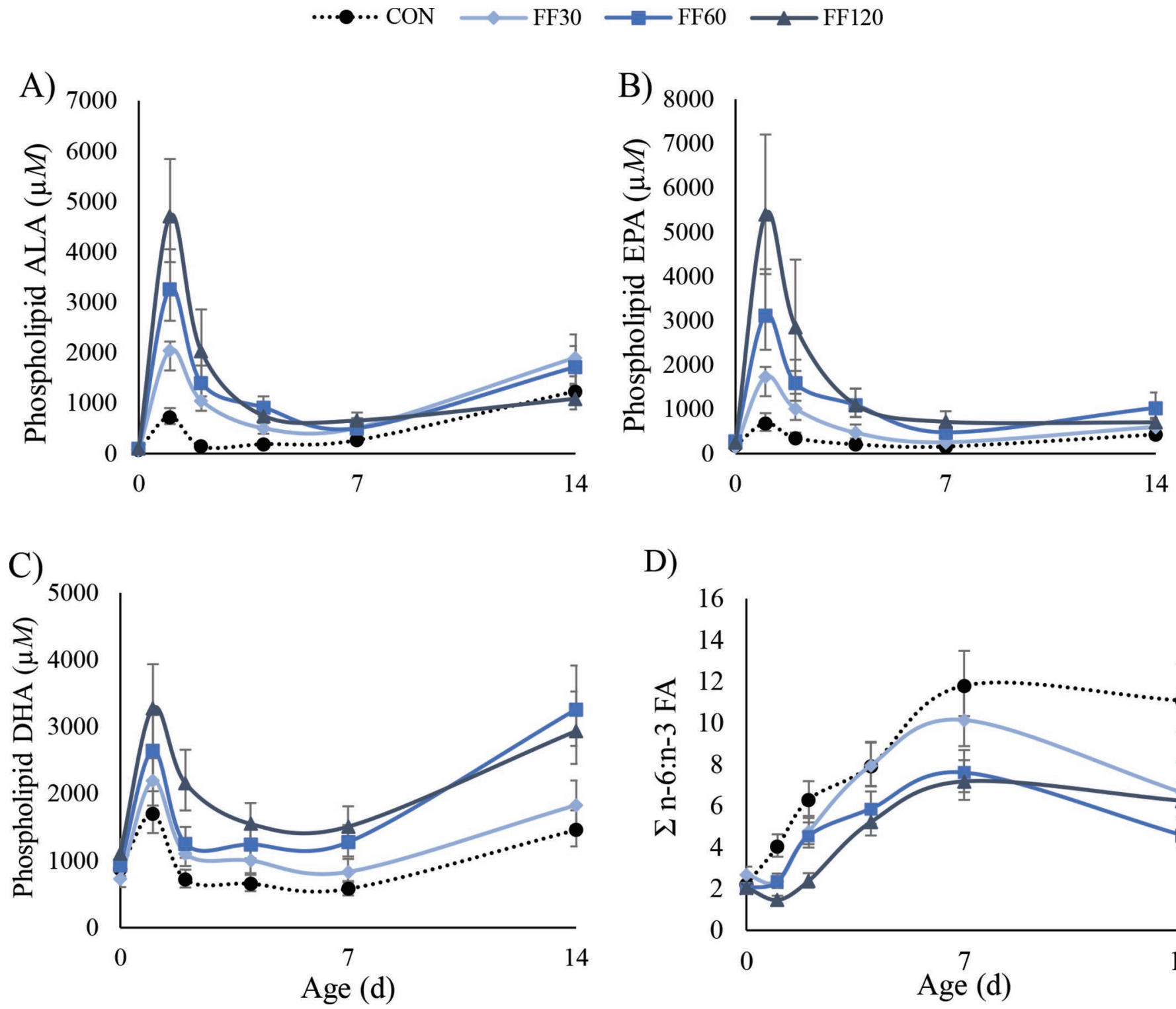

D)

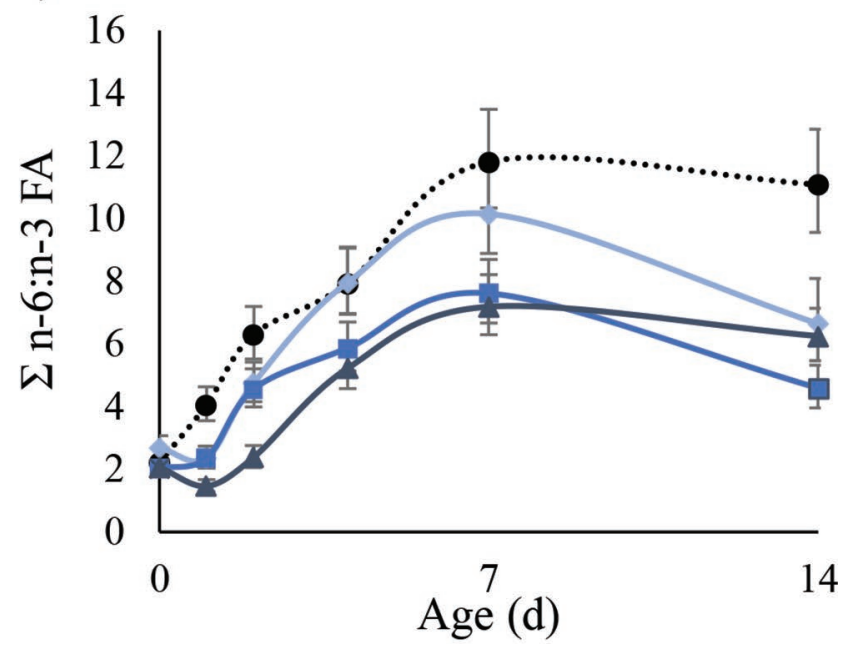

Figure 1. Treatment by day phospholipid fatty acid (FA) concentration $(\mu M)$ LSM of $\alpha$-linolenic acid (ALA; A), eicosapentaenoic acid (EPA; B), docosahexaenoic acid (DHA; C), and total n-6:total n-3 FA ratio (D) predicted from the model. The ALA, EPA, and DHA are backtransformed for interpretation with adjusted SE. During wk 1, fish and flaxseed oil treatments increased ALA, EPA, and DHA and decreased the $\mathrm{n}-6: \mathrm{n}-3 \mathrm{FA}$ ratio $(P<0.001)$. Treatments $(\mathrm{n}=6)$ : CON $=$ control, no supplement added to colostrum; FF30 $=30 \mathrm{~mL}$ of a $1: 1 \mathrm{ratio}$ fish and flaxseed oil blend added to colostrum; FF60 $=60 \mathrm{~mL}$ of a 1:1 ratio fish and flaxseed oil blend added to colostrum; FF120 = $120 \mathrm{~mL}$ of a 1:1 ratio fish and flaxseed oil blend added to colostrum. 
Table 2. Least squares means of plasma phospholipid fatty acid (FA) concentrations on average d 1, 2, 4, and 7

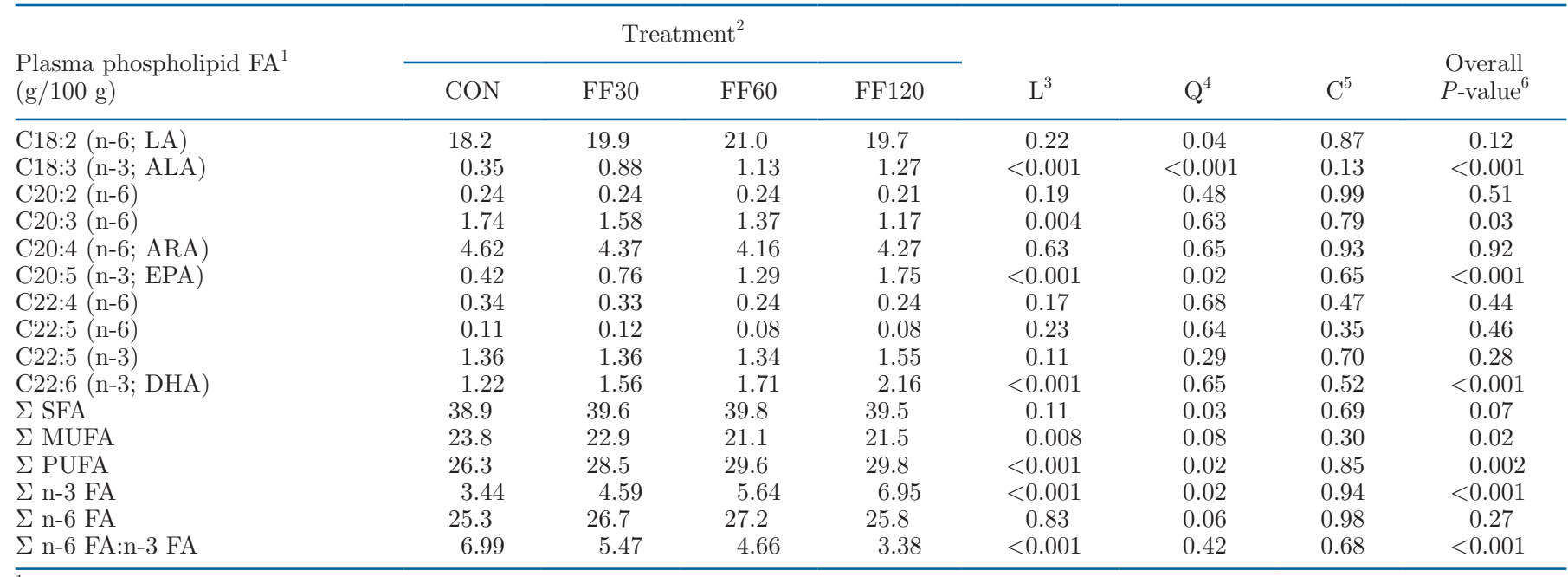

${ }^{1}$ Plasma phospholipid FA: linoleic acid (LA), $\alpha$-linolenic acid (ALA), arachidonic acid (ARA), eicosapentaenoic acid (EPA), and docosahexaenoic acid (DHA).

${ }^{2}$ Treatments $(\mathrm{n}=6): \mathrm{CON}=$ control, no supplement added to colostrum; FF30 $=30 \mathrm{~mL}$ of a 1:1 ratio fish and flaxseed oil blend added to colostrum; FF60 = $60 \mathrm{~mL}$ of a 1:1 ratio fish and flaxseed oil blend added to colostrum; FF120 = 120 mL of a 1:1 ratio fish and flaxseed oil blend added to colostrum.

${ }^{3} \mathrm{~L}=$ linear polynomial contrast.

${ }^{4} \mathrm{Q}=$ quadratic polynomial contrast.

${ }^{5} \mathrm{C}=$ cubic polynomial contrast.

${ }^{6}$ Overall $P$-value $=$ treatment effect $P$-value

5,6-lipoxin $\mathrm{A}_{4}\left(\mathbf{L X A}_{4}\right)$ increased $(P=0.02$ in linear fashion) with $\mathrm{FF}$ treatments by 106,104 , and $206 \%$ of CON.

Three enzymatic complexes produce the n- 6 and n-3 FA-derived oxylipids analyzed in this experiment. Oxylipids produced from cytochrome P450 epoxygenase (CYP) and lipoxygenase (LOX) were primarily affected by supplementation. No oxylipids analyzed that derived from cyclooxygenase (COX) pathways were altered in concentration by $\mathrm{FF}$ treatments.

The FF treatment did not decrease OSi during the first week of life $(P=0.35)$. The RONS concentrations and AOP remained constant across treatment groups ( $P=0.71$ and $P=0.40$, respectively). Least squares means of indicators of oxidative stress, including 8-isoprostaglandin- $\mathrm{A}_{2}$, are shown as treatment by sampling day in Figure 3.

\section{DISCUSSION}

Increasing doses of 30,60 , and $120 \mathrm{~mL}$ of $1: 1$ fish: flaxseed oil blend supplemented in colostrum did not affect health or growth in calves, decreased phospholipid n-6 FA:n-3 FA profile, increased free and phospholipid n-3 FA concentrations, and increased several oxylipids deriving from n-3 FA during the first week of life. Though OSi was unaltered by FF treatments, concentrations of an n-6 FA-derived isoprostane, 8-iso$\mathrm{PGA}_{2}$, were reduced, indicating oxidative stress was decreased in FF calves the first week of life.

Our previous experiment, which supplemented $60 \mathrm{~mL}$ of a 1:1 ratio fish:flaxseed oil blend with an additional 200 mg of $\alpha$-tocopherol (Opgenorth et al., 2020), observed increased free ALA, EPA, and DHA in plasma similar to the current study. We also analyzed phospholipid FA content, which is of particular interest because, once incorporated in phospholipid membranes, phospholipid PUFA and esterified forms cleaved by phospholipase A2 become available for enzymatic oxidation. Oxylipids become products of oxidation and are able to mediate inflammation and oxidative stress (Raphael and Sordillo, 2013). With an increase in the n-3 FA in plasma phospholipids of FF calves, we observed an increase in some n-3 FA-derived oxylipid concentrations. Raphael et al. (2014) proposed that manipulation of oxylipids may be feasible via dietary PUFA, and we found that with one n-3 FA supplementation, several oxylipid concentrations were altered. Though we observed oxylipids in plasma, Contreras et al. (2012) similarly found that increasing n-3 FA in the phospholipid profile of endothelial cells leads to increased beneficial n-3 FA-derived oxylipid concentrations. They also observed a decrease 
in reactive oxygen species (Contreras et al., 2012), though we did not find a corresponding RONS decrease in plasma in our experiment.

Oxylipids are products of PUFA substrates of enzymes such as LOX, COX, and CYP. These are cell signaling molecules able to mediate inflammation and its resolution through a variety of mechanisms. Oxylipids that increased in concentration by FF30, FF60, and FF120 were primarily end products of metabolism of EPA and DHA. The 14,15-DiHETE, 17,18-DiHETE, and 5,6-DiHETE from EPA and 19,20-DiHDPA from
DHA increased linearly with increased n-3 FA supplementation. Of the aforementioned oxylipids, all are end products of CYP enzymatic activity. The n-3 FA are more favorable substrates to LOX and CYP enzymes when compared with n-6 FA substrates (Zhang et al., 2014), but COX favors n-6 FA (Wada et al., 2007). This may explain why no oxylipids formed from COX pathways were altered by increasing n-3 FA supplementation. Dietary supplementation of linoleic acid causes an observed increase in COX activity (Marchix et al., 2015), and DHA decreases COX expression (Massaro
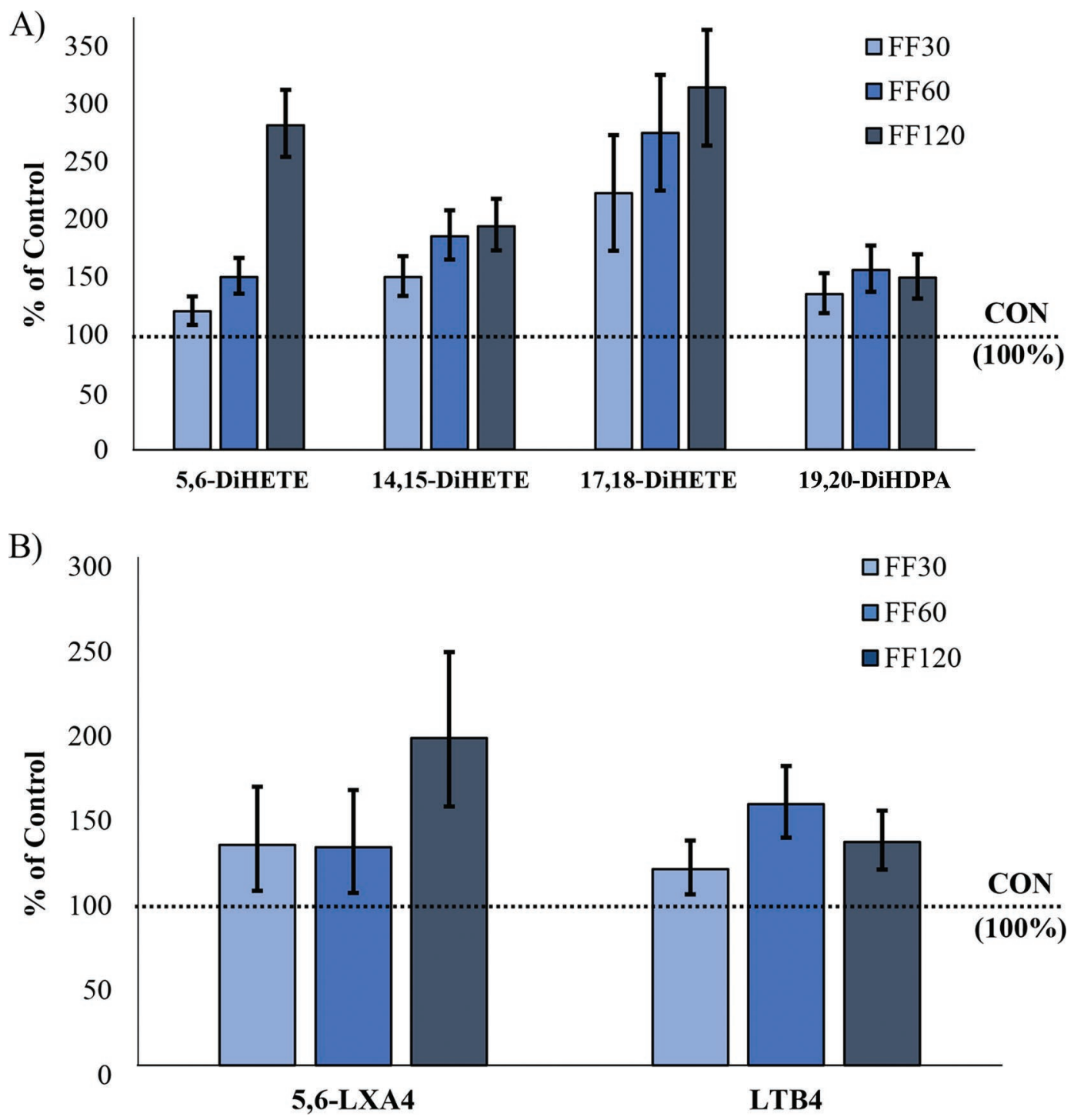

Figure 2. Fish and flaxseed oil treatments depicted as a LSM percentage of control (CON) \pm SEM for n-3 fatty acid (FA)-derived oxylipids (A) and n-6 FA-derived oxylipids (B) that differed from CON concentrations during the first week of age. Oxylipids were dihydroxy-eicosatetraenoic acid (DiHETE), dihydroxy-docosapentaenoic acid (DiHDPA), lipoxin (LX), and leukotriene (LT). Overall treatment $P$-values were as follows: 5,6-DiHETE: $P<0.01 ; 14,15$-DiHETE: $P<0.001 ; 17,18$-DiHETE: $P=0.01 ; 19,20$-DiHDPA: $P=0.01 ; 5,6$-LXA4: $P=0.06$; LTB4: $P=0.02$. Treatments $(\mathrm{n}=6)$ : CON $=$ no supplement added to colostrum; FF30 $=30 \mathrm{~mL}$ of a 1:1 ratio fish and flaxseed oil blend added to colostrum; FF60 = $60 \mathrm{~mL}$ of a 1:1 ratio fish and flaxseed oil blend added to colostrum; FF120 = $120 \mathrm{~mL}$ of a 1:1 ratio fish and flaxseed oil blend added to colostrum. 

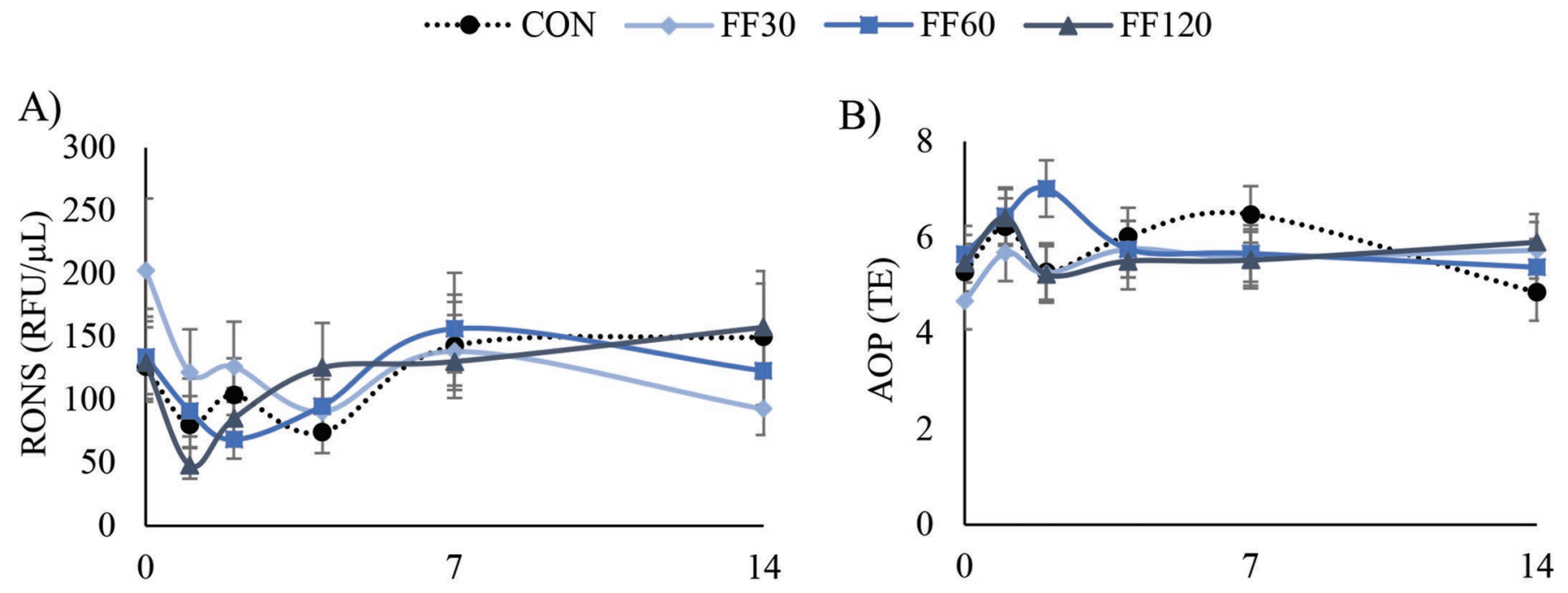

C)

D)
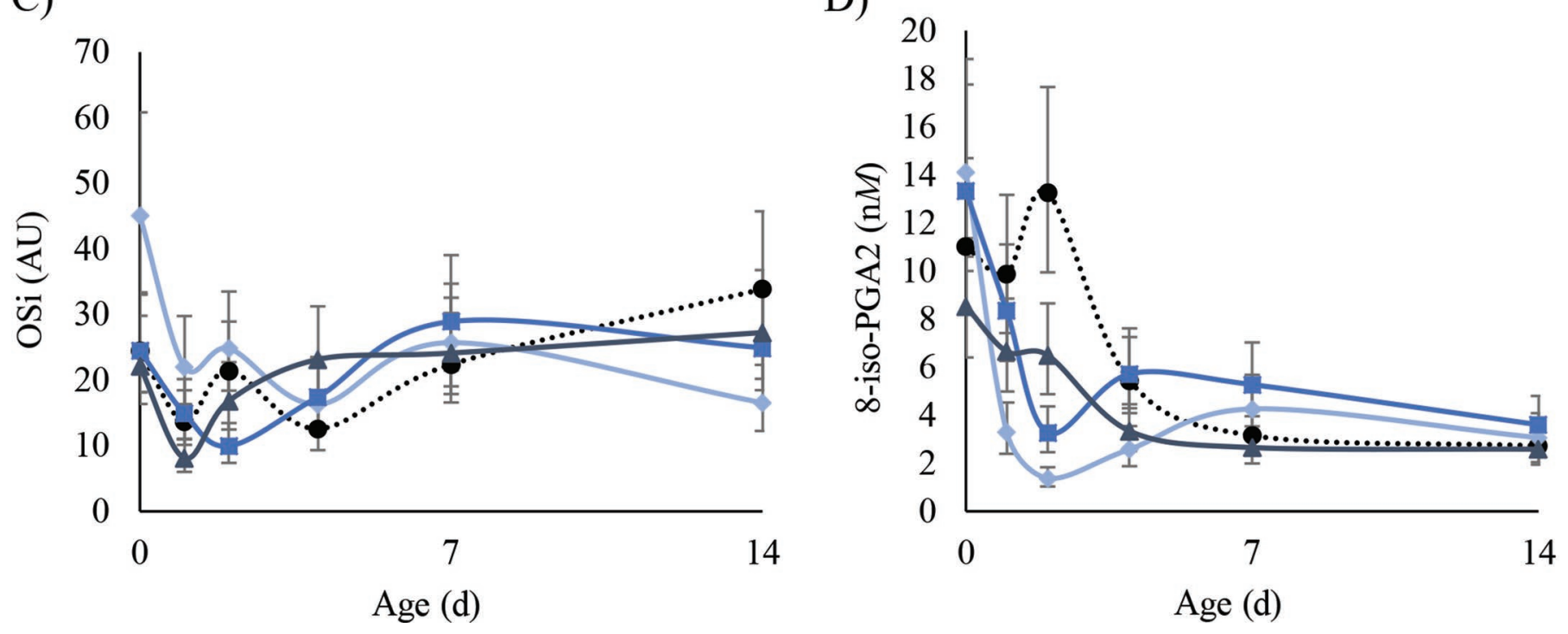

Figure 3. Least squares means of treatments during the first 2 wk of life of reactive oxygen and nitrogen species (RONS, A), antioxidant potential (AOP, B), oxidant status index (OSi, C), and 8-iso-prostaglandin A2 (8-iso-PGA2, D), which are all indicators of oxidative stress. The RONS, OSi, and 8-iso-PGA2 means are back-transformed from the model for interpretation with adjusted SE. The fish and flaxseed oil treatments did not alter RONS, AOP, or OSi, but did decrease 8-iso-PGA2 $(P=0.01)$ during the first week of age. Treatments $(\mathrm{n}=6)$ : CON $=$ control, no supplement added to colostrum; FF30 $=30 \mathrm{~mL}$ of a 1:1 ratio fish and flaxseed oil blend added to colostrum; FF60 $=60 \mathrm{~mL}$ of a 1:1 ratio fish and flaxseed oil blend added to colostrum; FF120 $=120 \mathrm{~mL}$ of a 1:1 ratio fish and flaxseed oil blend added to colostrum. $\mathrm{RFU}=$ relative fluorescent units; $\mathrm{TE}=$ Trolox equivalents; $\mathrm{AU}=$ arbitrary units.

et al., 2006). Though we did not analyze gene expression, it is possible FF treatments may decrease COX expression due to an increase in DHA concentrations and a decrease in the ratio n-6:n-3 FA. Many painrelieving drugs such as aspirin or meloxicam function to inhibit COX activity (Brune and Patrignani, 2015), which is the very reason they are considered antiinflammatory. The only COX-produced oxylipid that linearly decreased with increasing FF supplementation was thromboxane-2, which has proinflammatory functions, though no overall difference $(P=0.21)$ in concentration among treatments was observed. Thus, further analysis of COX gene expression may be warranted to provide further evidence of the antiinflammatory effects of FF treatments in neonatal calves.

The oxylipids $\mathrm{LTB}_{4}$ and $\mathrm{LXA}_{4}$ also increased with FF supplementation. Interestingly, ARA, the source of these oxylipids, did not increase as plasma free PUFA 
or phospholipid PUFA in FF-supplemented calves compared with CON. The $\mathrm{LXA}_{4}$ is antiinflammatory and $\mathrm{LTB}_{4}$ has some known proinflammatory functions. The $\mathrm{LXA}_{4}$ functions to enhance epithelial cell wound healing in rodents (Gronert et al., 2005) and initiate remodeling of phospholipids in humans (Nigam et al., 1990) among many more actions (Gabbs et al., 2015). Contrastingly, $\mathrm{LTB}_{4}$ helps instigate neutrophil chemotaxis in bovines (Heidel et al., 1989).

Our study is perhaps the first to describe oxylipid and isoprostane concentrations during the first week of life of any neonate mammalian species. Oxylipid concentrations differ among cows in varying stages of lactation, and concentrations are not always necessarily indicative of physiological changes (Kuhn et al., 2017; Putman et al., 2019). Though calf oxylipid concentrations were found to be much smaller than adult cows (nM vs. $\mu M$ ), the periparturient stage of the dairy cow can yield some interesting parallels to neonatal calves. Kuhn et al. (2017) suggested $\mathrm{LXA}_{4}$ is preferentially produced in periparturient cows, perhaps as a mechanism to reduce the systemic inflammatory state observed after parturition. We found supplementing calves with n-3 FA in their first meal tended to increase $\mathrm{LXA}_{4}$ concentrations, which is curious considering $\mathrm{LXA}_{4}$ is derived from ARA. Supplementation with n-3 FA in rainbow trout and female rats decreases $\mathrm{LXA}_{4}$ and other ARA-derived lipoxygenase products (Ashton et al., 1994; Poulsen et al., 2008), which was consistent with the idea that ARA and n-3 FA compete for lipoxygenase binding (Schmitz and Ecker, 2008). However, calves receive a greater n-6:n-3 FA ratio in the diet, and supplementing n-3 FA in a short period of time in the current study is likely not enough to alter n-6 FA phospholipid content, and thus their oxylipid products, in all tissues. Nevertheless, $\mathrm{LXA}_{4}$ concentrations tended to increase with increasing n-3 FA supplementation, indicating preferential production of this metabolite similar to what has been observed in periparturient cows (Kuhn et al., 2017) during a time when reducing systemic inflammation is a key homeostatic goal.

Differing from oxylipids, isoprostanes are direct biomarkers of oxidative stress because their production results from RONS-induced peroxidation and damage to the phospholipid membrane and thus cellular components (Montuschi et al., 2004). A decrease in isoprostane concentration indicates reduced lipid peroxidation and thus oxidative damage that compromises normal cellular functions (van 't Erve, 2018). Alternatively, OSi, the concentration of RONS to AOP, is considered a measure of redox balance (Kuhn et al., 2018); therefore, we speculate FF treatments decreased oxidative stress due to decreased 8-iso-PGA2 in plasma, even though OSi remained unchanged.

Some evidence suggests neonate immune processes gravitate toward a proinflammatory state at birth (Braekke et al., 2006; Boro et al., 2014). The placenta favors prooxidant isoprostanes derived from n-6 FA pathways; in humans, 8-iso-prostaglandin- $\mathrm{F}_{2 \alpha}$, a prominent and well-studied isoprostane known to indicate increased free radical concentrations, is highly concentrated in the umbilical vein (Braekke et al., 2006). Placental production of this biomarker of oxidative stress may be regulated by hormones, though explanations as to why this phenomenon occurs are still unclear (Hermenegildo et al., 2002). The placenta may require a certain degree of inflammation to detach normally (Boro et al., 2014), and inflammation plays important and necessary roles in the calving process (Bradford et al., 2015). However, oxidative stress can affect calves well beyond the acute response at birth (Abuelo et al., 2013), and the additional supplementation of antioxidant and antiinflammatory nutrients after birth may be beneficial for resolving these pathways quickly to avoid decreased calf viability and a disadvantaged immune system.

\section{CONCLUSIONS}

A 1:1 fish:flaxseed oil supplement in colostrum at 30, 60 , and $120 \mathrm{~mL}$ linearly increased plasma concentrations of n-3 FA and decreased n-6:n-3 FA ratios in both free FA and phospholipid FA fractions. In addition, FF supplements decreased concentrations of isoprostane 8-iso-PGA2, a direct biomarker of lipid peroxidation during oxidative stress. However, FF supplements did not alter plasma oxidant status, health, or growth, regardless of the n-3 FA dose level. We conclude that supplementing n-3 FA in colostrum promoted an antiinflammatory state in the first week after birth, but that growth up to weaning was not enhanced. We suggest neonatal calves may benefit from n-3 FA supplementation in colostrum to encourage a greater antiinflammatory state and that effects on health should be tested with more calves per treatment.

\section{ACKNOWLEDGMENTS}

This project was supported by the Michigan Alliance for Animal Agriculture (\#AA18-032), Michigan Milk Producers Association, and Michigan State University AgBioResearch. The authors appreciate Lynn Worden and the Saskatoon Colostrum Company (Saskatoon, SK, Canada) for their contributions to sample analysis 
and the Michigan State University Dairy Cattle Teaching and Research Center (East Lansing) for calf care. The authors have not stated any conflicts of interest.

\section{REFERENCES}

Abuelo, A., J. Hernández, J. L. Benedito, and C. Castillo. 2013. Oxidative stress index as a new tool to assess redox status in dairy cattle during the transition period. Animal 7:1374-1378. https:// doi.org/10.1017/S1751731113000396.

Ashton, I. K., K. Clements, S. E. Barrow, C. J. Secombes, and A. F. Rowley. 1994. Effects of dietary fatty acids on eicosanoidgenerating capacity, fatty acid composition and chemotactic activity of rainbow trout (Oncorhynchus mykiss) leucocytes. Biochim. Biophys. Acta 1214:253-262. https://doi.org/10.1016/0005 -2760(94)90071-X.

Ballou, M., and E. DePeters. 2008. Supplementing milk replacer with omega-3 fatty acids from fish oil on immunocompetence and health of Jersey calves. J. Dairy Sci. 91:3488-3500.

Bielmann, V., J. Gillan, N. Perkins, A. Skidmore, S. Godden, and K. Leslie. 2010. An evaluation of brix refractometry instruments for measurement of colostrum quality in dairy cattle. J. Dairy Sci. 93:3713-3721.

Boro, P., A. Kumaresan, A. Singh, D. Gupta, S. Kumar, A. Manimaran, A. K. Mohanty, T. K. Mohanty, R. Pathak, N. M. Attupuram, R. K. Baithalu, and S. Prasad. 2014. Expression of short chain fatty acid receptors and pro-inflammatory cytokines in utero-placental tissues is altered in cows developing retention of fetal membranes. Placenta 35:455-460. https://doi.org/10.1016/j.placenta .2014.04.009.

Bradford, B. J., K. Yuan, J. K. Farney, L. K. Mamedova, and A. J. Carpenter. 2015. Invited review: Inflammation during the transition to lactation: New adventures with an old flame. J. Dairy Sci. 98:6631-6650. https://doi.org/10.3168/jds.2015-9683.

Braekke, K., N. K. Harsem, and A. C. Staff. 2006. Oxidative stress and antioxidant status in fetal circulation in preeclampsia. Pediatr. Res. 60:560-564. https://doi.org/10.1203/01.pdr.0000242299 .01219.6a.

Brune, K., and P. Patrignani. 2015. New insights into the use of currently available non-steroidal anti-inflammatory drugs. J. Pain Res. 8:105-118. https://doi.org/10.2147/JPR.S75160.

Buonocore, G., S. Perrone, and R. Bracci. 2001. Free radicals and brain damage in the newborn. Neonatology 79:180-186.

Calloway, C. D., J. W. Tyler, R. K. Tessman, D. Hostetler, and J. Holle. 2002. Comparison of refractometers and test endpoints in the measurement of serum protein concentration to assess passive transfer status in calves. J. Am. Vet. Med. Assoc. 221:1605-1608. https://doi.org/10.2460/javma.2002.221.1605.

Civelek, T., H. A. Celik, G. Avci, and G. C. Cingi. 2008. Effects of dystocia on plasma cortisol and cholesterol levels in Holstein heifers and their newborn calves. Bull. Vet. Inst. Pulawy 52:649-654.

Contarini, G., M. Povolo, V. Pelizzola, L. Monti, A. Bruni, L. Passolungo, F. Abeni, and L. Degano. 2014. Bovine colostrum: Changes in lipid constituents in the first 5 days after parturition. J. Dairy Sci. 97:5065-5072. https://doi.org/10.3168/jds.2013-7517.

Contreras, G., S. Mattmiller, W. Raphael, J. Gandy, and L. Sordillo. 2012. Enhanced n-3 phospholipid content reduces inflammatory responses in bovine endothelial cells. J. Dairy Sci. 95:7137-7150. https://doi.org/10.3168/jds.2012-5729.

Folch, J., M. Lees, and G. H. Sloane-Stanley. 1957. A simple method for the isolation and purification of total lipids from animal tissues. J. Biol. Chem. 226:497-509.

Frank, L., and R. S. Sosenko. 1987. Development of lung anti-oxidant enzyme system in late gestation: possible implications for the prematurely born infant. J. Pediatr. 110:9-14. https://doi.org/10 $.1016 /$ S0022-3476(87)80279-2.

Gabbs, M., S. Leng, J. G. Devassy, M. Monirujjaman, and H. M. Aukema. 2015. Advances in our understanding of oxylipins derived from dietary PUFAs. Adv. Nutr. 6:513-540. https://doi.org/ 10.3945/an.114.007732.
Godden, S. 2008. Colostrum management for dairy calves. Vet. Clin. North Am. Food Anim. Pract. 24:19-39. https://doi.org/10.1016/ j.cvfa.2007.10.005.

Gronert, K., N. Maheshwari, N. Khan, I. R. Hassan, M. Dunn, and M. Laniado Schwartzman. 2005. A Role for the mouse 12/15-lipoxygenase pathway in promoting epithelial wound healing and host defense. J. Biol. Chem. 280:15267-15278. https://doi.org/10.1074/ jbc.M410638200.

Hansen, V. L., L. S. Faber, A. A. Salehpoor, and R. D. Miller. 2017. A pronounced uterine pro-inflammatory response at parturition is an ancient feature in mammals. Proc. Biol. Sci. 284:20171694. https:/ /doi.org/10.1098/rspb.2017.1694.

Heidel, J. R., S. M. Taylor, W. W. Laegreid, R. M. Silflow, H. Denny Liggitt, and R. Wes Leid. 1989. In vivo chemotaxis of bovine neutrophils induced by 5-lipoxygenase metabolites of arachidonic and eicosapentaenoic acid. Am. J. Pathol. 134:671-676.

Hermenegildo, C., M. C. García-Martínez, J. J. Tarín, and A. Cano. 2002. Estradiol reduces F2 $\alpha$-isoprostane production in cultured human endothelial cells. Am. J. Physiol. Heart Circ. Physiol. 283:H2644-H2649. https://doi.org/10.1152/ajpheart.00369.2002.

Hill, T., M. VandeHaar, L. Sordillo, D. Catherman, H. Bateman, and R. Schlotterbeck. 2011. Fatty acid intake alters growth and immunity in milk-fed calves. J. Dairy Sci. 94:3936-3948.

Karcher, E. L., T. Hill, H. Bateman II, R. Schlotterbeck, N. Vito, L. Sordillo, and M. VandeHaar. 2014. Comparison of supplementation of n-3 fatty acids from fish and flax oil on cytokine gene expression and growth of milk-fed Holstein calves. J. Dairy Sci. 97:2329-2337. https://doi.org/10.3168/jds.2013-7160.

Kramer, J. K., V. Fellner, M. E. Dugan, F. D. Sauer, M. M. Mossoba, and M. P. Yurawecz. 1997. Evaluating acid and base catalysts in the methylation of milk and rumen fatty acids with special emphasis on conjugated dienes and total trans fatty acids. Lipids 32:1219-1228. https://doi.org/10.1007/s11745-997-0156-3.

Kuhn, M. J., V. Mavangira, G. C. Gandy, C. Zhang, A. D. Jones, and L. M. Sordillo. 2017. Differences in the oxylipid profiles of bovine milk and plasma at different stages of lactation. J. Agric. Food Chem. 65:4980-4988. https://doi.org/10.1021/acs.jafc.7b01602.

Kuhn, M. J., V. Mavangira, J. C. Gandy, and L. M. Sordillo. 2018. Production of 15-F-isoprostane as an assessment of oxidative stress in dairy cows at different stages of lactation. J. Dairy Sci. 101:9287-9295. https://doi.org/10.3168/jds.2018-14669.

Ling, T., M. Hernandez-Jover, L. M. Sordillo, and A. Abuelo. 2018. Maternal late-gestation metabolic stress is associated with changes in immune and metabolic responses of dairy calves. J. Dairy Sci. 101:6568-6580. https://doi.org/10.3168/jds.2017-14038.

Lock, A. L., C. Preseault, J. Rico, K. DeLand, and M. Allen. 2013. Feeding a C16:0-enriched fat supplement increased the yield of milk fat and improved conversion of feed to milk. J. Dairy Sci. 96:6650-6659. https://doi.org/10.3168/jds.2013-6892.

Marchix, J., B. Choque, M. Kouba, A. Fautrel, D. Catheline, and P. Legrand. 2015. Excessive dietary linoleic acid induces proinflammatory markers in rats. J. Nutr. Biochem. 26:1434-1441. https:// doi.org/10.1016/j.jnutbio.2015.07.010.

Massaro, M., A. Habib, L. Lubrano, S. D. Turco, G. Lazzerini, T. Bourcier, B. B. Weksler, and R. De Caterina. 2006. The omega-3 fatty acid docosahexaenoate attenuates endothelial cyclooxygenase-2 induction through both $\mathrm{NADP}(\mathrm{H})$ oxidase and PKC inhibition. Proc. Natl. Acad. Sci. USA 103:15184-15189. https://doi .org/10.1073/pnas.0510086103.

Mavangira, V., J. C. Gandy, C. Zhang, V. E. Ryman, A. Daniel Jones, and L. M. Sordillo. 2015. Polyunsaturated fatty acids influence differential biosynthesis of oxylipids and other lipid mediators during bovine coliform mastitis. J. Dairy Sci. 98:6202-6215. https://doi .org/10.3168/jds.2015-9570.

Moallem, U., and M. Zachut. 2012. The effects of supplementation of various n- 3 fatty acids to late-pregnant dairy cows on plasma fatty acid composition of the newborn calves. J. Dairy Sci. 95:40554058. https://doi.org/10.3168/jds.2012-5457.

Montuschi, P., P. J. Barnes, and L. J. Roberts. 2004. Isoprostanes: Markers and mediators of oxidative stress. FASEB J. 18:17911800. https://doi.org/10.1096/fj.04-2330rev. 
Nigam, S., S. Fiore, F. W. Luscinskas, and C. N. Serhan. 1990. Lipoxin A4 and lipoxin B4 stimulate the release but not the oxygenation of arachidonic acid in human neutrophils: Dissociation between lipid remodeling and adhesion. J. Cell. Physiol. 143:512-523. https:// doi.org/10.1002/jcp.1041430316.

O'Donnell, V. B., B. Maskrey, and G. W. Taylor. 2009. Eicosanoids: Generation and detection in mammalian cells. Methods Mol. Biol. 462:5-23.

Opgenorth, J., L. M. Sordillo, and M. J. VandeHaar. 2020. Colostrum supplementation with $\mathrm{n}-3$ fatty acids and $\alpha$-tocopherol alters plasma polyunsaturated fatty acid profile and decreases an indicator of oxidative stress in newborn calves. J. Dairy Sci. 103:3545-3553. https://doi.org/10.3168/jds.2019-17380.

Poulsen, R. C., K. H. Gotlinger, C. N. Serhan, and M. C. Kruger. 2008. Identification of inflammatory and proresolving lipid mediators in bone marrow and their lipidomic profiles with ovariectomy and omega-3 intake. Am. J. Hematol. 83:437-445. https://doi.org/ 10.1002/ajh.21170.

Putman, A. K., J. Brown, J. C. Gandy, A. Abuelo, and L. M. Sordillo. 2019. Oxylipid profiles of dairy cattle vary throughout the transition into early mammary gland involution. J. Dairy Sci. 102:24812491. https://doi.org/10.3168/jds.2018-15158.

Putman, A. K., J. L. Brown, J. C. Gandy, L. Wisnieski, and L. M. Sordillo. 2018. Changes in biomarkers of nutrient metabolism, inflammation, and oxidative stress in dairy cows during the transition into the early dry period. J. Dairy Sci. 101:9350-9359. https: //doi.org/10.3168/jds.2018-14591.

Raphael, W., L. Halbert, G. Contreras, and L. Sordillo. 2014. Association between polyunsaturated fatty acid-derived oxylipid biosynthesis and leukocyte inflammatory marker expression in periparturient dairy cows. J. Dairy Sci. 97:3615-3625. https://doi.org/10 .3168/jds.2013-7656.

Raphael, W., and L. Sordillo. 2013. Dietary polyunsaturated fatty acids and inflammation: The role of phospholipid biosynthesis. Int. J. Mol. Sci. 14:21167-21188. https://doi.org/10.3390/ijms141021167.

Re, R., N. Pellegrini, A. Proteggente, A. Pannala, M. Yang, and C. Rice-Evans. 1999. Antioxidant activity applying an improved
ABTS radical cation decolorization assay. Free Radic. Biol. Med. 26:1231-1237. https://doi.org/10.1016/S0891-5849(98)00315-3.

Schmitz, G., and J. Ecker. 2008. The opposing effects of $n-3$ and $n-6$ fatty acids. Prog. Lipid Res. 47:147-155. https://doi.org/10.1016/ j.plipres.2007.12.004.

University of Wisconsin Madison. 2020. Calf Health Scoring Chart. Accessed May 5, 2020. https://www.vetmed.wisc.edu/fapm/wp -content/uploads/2020/01/CalfHealthScoringChart-2018-EN-std .pdf.

van 't Erve, T. J. 2018. Strategies to decrease oxidative stress biomarker levels in human medical conditions: A meta-analysis on 8-iso-prostaglandin F2 $\alpha$. Redox Biol. 17:284-296. https://doi.org/ 10.1016/j.redox.2018.05.003.

Wada, M., C. J. DeLong, Y. H. Hong, C. J. Rieke, I. Song, R. S. Sidhu, C. Yuan, M. Warnock, A. H. Schmaier, C. Yokoyama, E. M. Smyth, S. J. Wilson, G. A. FitzGerald, R. M. Garavito, D. X. Sui, J. W. Regan, and W. L. Smith. 2007. Enzymes and receptors of prostaglandin pathways with arachidonic acid-derived versus eicosapentaenoic acid-derived substrates and products. J. Biol. Chem. 282:22254-22266. https://doi.org/10.1074/jbc.M703169200.

Zhang, G., S. Kodani, and B. D. Hammock. 2014. Stabilized epoxygenated fatty acids regulate inflammation, pain, angiogenesis and cancer. Prog. Lipid Res. 53:108-123. https://doi.org/10.1016/j .plipres.2013.11.003.

\section{ORCIDS}

Julie Opgenorth () https://orcid.org/0000-0002-2271-4720

Lorraine M. Sordillo (๑) https://orcid.org/0000-0001-8873-3134

Adam L. Lock ๑ https://orcid.org/0000-0002-9282-399X

Jeff C. Gandy @ https://orcid.org/0000-0003-0558-9611

Michael J. VandeHaar (i) https://orcid.org/0000-0002-8475-3493 